\title{
Removal of Chromium (VI) cation metal using Poly (N-vinyl-2- pyrrolidone)/Magnetite nanocomposite from aqueous media
}

\author{
Padmalaya $\mathrm{G}^{1}$, Sreeja $\mathrm{BS}^{1 *}$, Radha $\mathrm{S}^{1}$, Raamdheep $\mathrm{G}^{2}$, Saranya $\mathrm{J}^{3}$ \\ Department of Electronics and Communication Engineering, SSN College of Engineering, Kalavakkam-603110, \\ India. \\ 1'padmalayag@ssn.edu.in , 'sreejabs@ssn.edu.in \\ Center for Green Technology, Pondicherry University, Kalapet, Pondicherry-605014, India. \\ 2raamdheep@gmail.com \\ Department of Electronics and Communication Engineering, Rajalakshmi College of Engineering, Thandalam, \\ Chennai-602105, India. \\ ${ }^{3}$ saranyaj@rajalakshmi.edu.in
}

\begin{abstract}
Groundwater contamination with heavy metals is considered as serious environmental hazard that affect the human society. Nano adsorbents incorporating magnetite nanoparticles provides promising alternative to facilitate removal of heavy metal ions from wastewater. The present work focuses on removal of chromium (VI) cationic metals from aqueous media using Polyvinyl Pyrrolidone (PVP)/Magnetite $\left(\mathrm{Fe}_{3} \mathrm{O}_{4}\right)$ Nanocomposite (MNC). Magnetite nanoparticles are synthesized using chemical co-precipitation and grafted using polyvinyl pyrrolidone to form a magnetite nanocomposite. MNC were characterized with X-ray diffraction (XRD) and Infrared absorption spectrum (FT-IR) studies to affirm the formation and presence of polymeric functional groups of PVP/Magnetite nanocomposite. Batch experiments are carried out at exclusive concentration intervals to study about the adsorption efficiency of MNC on chromium (VI) cationic metal using U-Vis spectroscopy. The results obtained through adsorption studies shows the synthesized PVP/Magnetite nanocomposites has a removal efficiency of $94 \%$.
\end{abstract}

\section{INTRODUCTION}

Due to rapid increase in industrialization different contaminants are released into environment and pollute ground water. The presence of toxic trace metals like lead $(\mathrm{Pb})$, chromium $(\mathrm{Cr})$, mercury $(\mathrm{Hg})$, Zinc $(\mathrm{Zn})$ and cadmium $(\mathrm{Cd})$ in the ground water have high toxicity and non-degradable properties which can cause severe health hazards to animals and human society. Chromium is one of the most common trace metal found in ground water particularly in industrialized areas. Chromium exists in $+\mathrm{Il}$, + III, and $+\mathrm{VI}$ states, among these states $+\mathrm{VI}$ state is considered to be most toxic and acts as carcinogens, mutagens, and teratogens due to its strong oxidizing properties [1-5]. Removal of chromium ions is carried out using methods like chemical precipitation, ion-exchange, membrane filtration/ultrafiltration, solvent extraction, sedimentation, reduction, reverse osmosis, dialysis/electrodialysis and adsorption [6-9].Among these techniques, adsorption is most popular due to its controlled mechanism, increased ion removal rate, higher regeneration capacity and cost effectiveness [10-11].Activated carbon is the widely used material to remove metal ions. However activated carbon tends to be expensive material and also requires complexing agents to increase removal efficiency. Therefore it is necessary to find alternative adsorbents which are capable of having high metal binding capacities and removal effectiveness at low cost. Compared to traditional adsorbents nanostructured adsorbents exhibited higher efficiency and adsorption capacity at faster rates in ground water treatment. Nano-adsorbents should satisfy few criterions like should be non-toxic, selectivity to low concentration pollutants, easy removal of pollutants and infinitely recycled. Magnetite Nanoadsorbents have attracted researchers due to its multifunctional properties such as super paramagnetic, recyclability, easy processing and low toxicity. Magnetite nanoparticles (MNP) oxidize easily and form aggregates due to dipole-dipole interaction. The stability of the MNP is enhanced by tailoring the surface using natural or synthetic stabilizers like surfactants and polymers with functional groups. The synergistic properties of magnetite nanocomposite containing organic-inorganic materials improve additional properties that cannot be achieved in either single organic or individual inorganic components [17]. Research is being carried out in enhancing the trace metal removal efficiency of magnetite nanocomposite using polymers [12-13]. Polymers like polypyrrole (PPy), polyaniline (PANI), Chitosan, montmorillonite were incorporated with magnetite nanoparticles are found to be high efficient adsorbent in removal of $\mathrm{Cr}(\mathrm{VI})$ ions [18, 22 23, 6]. These polymers form environmental friendly and are easy to prepare which provides functionalized media for the enhanced removal of chromium ions. Fe NPs are coated with well-defined $\mathrm{SiO}_{2}$ shells were used as suitable adsorbent for removal of chromium ions [2]. Magnetite nanoparticles were modified with amorphous FeB alloy and used as efficient adsorbents for chromium removal [19]. Surface modification of magnetite nanoparticles with ionic ligands like trimethoxysilane and hydrophilic compounds PEI were also used as good adsorbents for removal of $\mathrm{Cr}$ (VI) ions [20-21]. Herein we report the novel experimental results that interaction of PVP on magnetite nanoparticles provides $94 \%$ of efficiency towards the removal of $\mathrm{Cr}(\mathrm{VI})$ ions which was not reported before and it has been achieved with different concentration levels of PVP/Magnetite nanocomposite in aqueous media and analyzed using UVis-Spectroscopy. As poly (N-vinyl-2-pyrrolidone) is a polar polymer, due to its carbonyl group of double group in the pyrrolidone group. It has the active carbonyl or tertiary nitrogen group. It was reported [24] PVP has three compounds (O, N, and carbonyl) that take part in interaction with magnetite nanoparticles. We made comparative study [Table 1] with other nanocomposites efficiency on removing chromium ions. 


\begin{tabular}{|c|c|c|c|c|c|}
\hline S.No. & Materials used & $\begin{array}{c}\text { Initial Concentration } \\
\text { used }\end{array}$ & Adsorbent dose & $\begin{array}{l}\text { Removal (\%) } \\
\text { achieved }\end{array}$ & References \\
\hline 1. & $\begin{array}{l}\text { Polypyrrole magnetic } \\
\text { nanocomposite }\end{array}$ & $200 \mathrm{mg} / \mathrm{L}$ & $0.1 \mathrm{~g} / \mathrm{L}$ & 100 & 18 \\
\hline 2. & $\begin{array}{c}\mathrm{Fe}_{3} \mathrm{O}_{4}-\mathrm{FeB} \\
\text { nanocomposite }\end{array}$ & $32 \mathrm{mg} / \mathrm{L}$ & - & 100 & 19 \\
\hline 3. & $\begin{array}{c}\text { Magnetite- } \\
\text { Polyethylenimine- } \\
\text { Montmorillonite: Hybrid } \\
\text { film }\end{array}$ & $12 \mathrm{mg} / \mathrm{L}$ & $4 \mathrm{~g} / \mathrm{L}$ & 80 & 20 \\
\hline 4. & $\begin{array}{l}\text { Iron core-shell } \\
\text { nanocomposite }\end{array}$ & $70 \mathrm{mg} / \mathrm{L}$ & $0.15 \mathrm{~g} / \mathrm{L}$ & 100 approx. & 2 \\
\hline 5. & $\begin{array}{l}\text { Montmorillonite supported } \\
\text { magnetite nanocomposite }\end{array}$ & $50 \mathrm{mg} / \mathrm{L}$ & $5 \mathrm{~g} / \mathrm{L}$ & 99.8 & 6 \\
\hline 6. & $\begin{array}{c}\text { Ionically modified } \\
\text { magnetite nanocomposite }\end{array}$ & $100 \mathrm{mg} / \mathrm{L}$ & - & 97 & 21 \\
\hline 7. & $\begin{array}{l}\text { PPY/maghemite } \\
\text { PANI/maghemite } \\
\text { nanocomposite }\end{array}$ & $50 \mathrm{mg} / \mathrm{L}$ & $2 \mathrm{mg} / \mathrm{L}$ & $\begin{array}{l}82 \\
49\end{array}$ & 22 \\
\hline 8. & $\begin{array}{l}\text { Chitosan-magnetite } \\
\text { nanocomposite strip }\end{array}$ & $0.04 \mathrm{~g} / \mathrm{L}$ & $0.01 \mathrm{~g} / \mathrm{L}$ & 92.3 & 23 \\
\hline 9. & $\begin{array}{c}\text { Polyvinyl } \\
\text { pyrrolidone/magnetite } \\
\text { nanocomposite }\end{array}$ & $40 \mathrm{mg} / \mathrm{L}$ & $0.4 \mathrm{~g} / \mathrm{L}$ & 94 & This work \\
\hline
\end{tabular}

\section{Experimental}

\section{Materials:}

Ferrous sulphate $\left(\mathrm{Fe}_{2} \mathrm{SO}_{4} \cdot 7 \mathrm{H}_{2} \mathrm{O}\right)$, ferric chloride $\left(\mathrm{FeCl}_{3} \cdot 6 \mathrm{H}_{2} \mathrm{O}\right)$, ammonium hydroxide $\left(\mathrm{NH}_{4} \mathrm{OH}\right)$, potassium dichromate $\left(\mathrm{K}_{2} \mathrm{Cr}_{2} \mathrm{O}_{7}\right)$ and polyvinyl pyrrolidone $\left(\mathrm{C}_{6} \mathrm{H}_{9} \mathrm{NO}\right)_{n}$ were purchased from Sigma-Aldrich. All the chemicals purchased for synthesis of magnetite nanocomposite are analytical grade and used without further purification.

\section{Material synthesis:}

Magnetite nanoparticles were synthesized using Chemical Co-Precipitation technique. Fig () shows the schematics on preparation of magnetite nanoparticles. In this technique, precursors of ferric chloride and ferrous sulphate were taken in the ratio of $(2: 1)$ and stirred well for 20 mins. With the continuous stirring, $10 \%$ of Ammonium Hydroxide $\left(\mathrm{NH}_{4} \mathrm{OH}\right)$ was added in drop wise and black precipitate is formed indicating the formation of magnetite nanoparticles. Formed Magnetite nanoparticles were collected using decanted with magnet and washed three times with double distilled water $\left(\mathrm{ddH}_{2} \mathrm{O}\right)$. In order to form hybrid nanocomposite, 0.5\% PVP was added along with magnetite nanoparticles and stirred for 1 hour and made into powder form by drying in hot air oven at $80^{\circ} \mathrm{C}$. The final product in the powder form was used for further analysis.

\section{Batch Adsorption Experiments}

Adsorption of $\mathrm{Cr}^{6+}$ ions were performed in batch mode with desired concentration of PVP/magnetite nanocomposite. The studies were performed by shaking predetermined adsorbents in $50 \mathrm{~mL}$ of metal ion solution containing desired concentration of adsorbents $(0 \sim 1.5 \mathrm{~g} / \mathrm{L})$ The efficiency in removal of heavy metal using PVP and PVP_ magnetite nanocomposites were evaluated using UV-visible spectroscopy. The removal efficiency is calculated using the equ (1).

$$
E=\left(C_{0}-C_{e} / C_{0}\right) / 100
$$

Where $\mathrm{C}_{0}$ is the initial $\mathrm{Cr}(\mathrm{VI})$ concentration of the Solution and $\mathrm{C}_{\mathrm{e}}$ represents the remaining $\mathrm{Cr}(\mathrm{VI})$ existing in solution after the adsorption process.

\section{Results and discussion}

X-Ray Diffraction patterns of sample shown in the Fig.1.shows PVP/magnetite nanocomposites denotes the diffraction planes of (220), (311), (400), (422), (511), (440), (553), (444) were matched with standard reference pattern JCPDS 892355 reported for inverse spinel structure. 


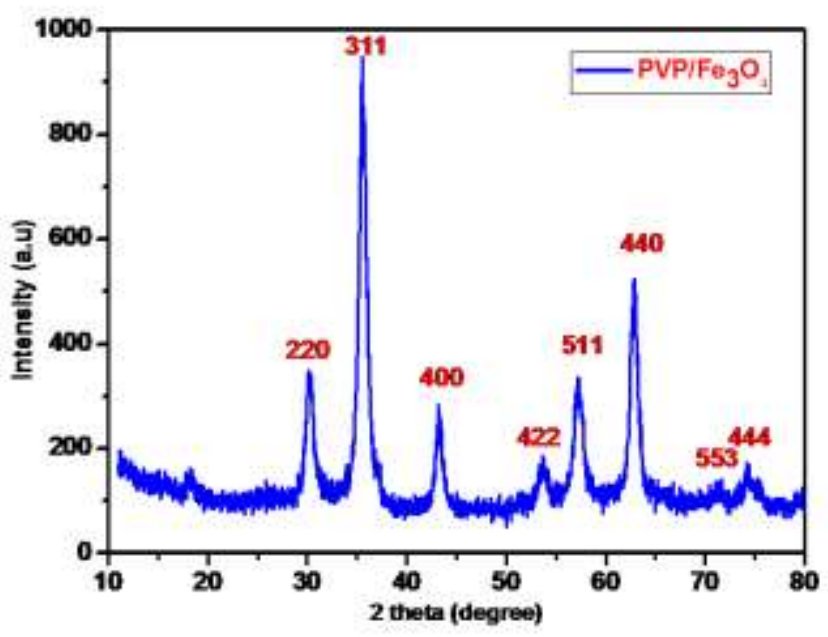

Fig.1. X-Ray diffraction patterns of PVP/Magnetite nanocomposite

Crystallite size of $10.7 \mathrm{~nm}$ was calculated by using Scherrer formula for preferential orientation plane of (311). Lattice constant values of nanocomposite were calculated $(a, b=8.386,8.375)$ of inverse spinel structure and were in good agreement with literature.

The results of FTIR confirm the functional groups of PVP with Magnetite nanoparticles (fig.2). The most striking evidence from FTIR spectrum of PVP-Magnetite nanocomposite is that the broad peak between $1285 \mathrm{~cm}^{-1}$ and $1650 \mathrm{~cm}^{-1}$ confirms the $\mathrm{C}-\mathrm{N}$ stretching vibration and $\mathrm{C}=\mathrm{O}$ stretching vibration of PVP, respectively [17]. The narrow absorption peak centered at 1285 and $686 \mathrm{~cm}^{-1}$ were occurred due to the C-N bonding and Fe-O vibrations [21] of PVP and magnetite nanoparticles attributed to coordinate bond between nitrogen-carbon atoms of PVP and Fe-O ions. As a consequence, the FTIR qualitatively confirms the formation of PVP-Magnetite nanocomposites.

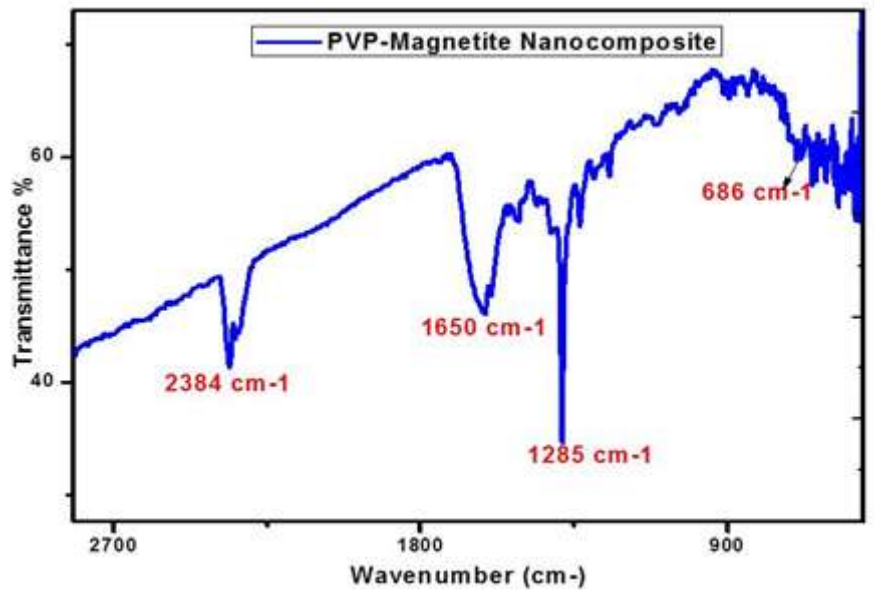

Fig. 2. FTIR study for PVP-Magnetite nanocomposite

\section{Effect of initial concentration and metal removal mechanism:}

The PVP/Magnetite nanocomposite is employed for $\mathrm{Cr}^{6+}$ removal using the UV-visible absorption spectrophotometer (JASCO V 650) with the $10 \mathrm{mg} / \mathrm{L}$ in $50 \mathrm{~mL}$ of $\mathrm{Cr}^{6+}$ solution and alternatives after treatment with PVP/Magnetite nanocomposite under ultrasonication for $5 \mathrm{~min}$. The evaluation of $\mathrm{Cr}(\mathrm{VI})$ removal in the solution was using the colorimetric method with a characteristic peak at 350nm in the U-Vis absorption curve. The higher the $\mathrm{Cr}(\mathrm{VI})$ focus in the perfect solution, the better peak intensity was noticed. The solution of $\mathrm{Cr}^{6+}$ containing $10 \mathrm{mg} / \mathrm{L}$ showed greatest absorbance at 2.18, on treating with PVP/Magnetite nanocomposite at different concentrations $(0 \sim 2.5 \mathrm{~g} / \mathrm{L})$ under ultrasonication for $5 \mathrm{~min}$, the peak intensity reduced little by little with increasing the adsorbent concentration indicating the reduced $\mathrm{Cr}(\mathrm{VI})$ amount in the solution.

Fig.3. Shows the kinetics of adsorbent that describes the $\mathrm{Cr}(\mathrm{VI})$ uptake rate is one of the important characteristics which controls the property of absorbate moments uptake at the solid-solution interface. Hence, in our study, the kinetics of $\mathrm{Cr}(\mathrm{VI})$ removing was accomplished to understand the adsorption behavior of the prepared PVP/Magnetite nanocomposite. On the basis of above experimental results, it is believed that PVP-Magnetite nanocomposite shows high adsorption towards the $\mathrm{Cr}(\mathrm{VI})$ ions. Chromium (VI) exists in aqueous solutions as $\mathrm{Cr}_{2} \mathrm{O}_{7}{ }^{2-}$, 
$\mathrm{HCrO}^{4-}, \mathrm{CrO}_{4}{ }^{2-}$ and $\mathrm{HCr}_{2} \mathrm{O}_{7}^{-}[23,46]$. So, here high adsorption of $94 \%$ of PVP-Magnetite nanocomposite was believed to come from strong interaction between functional groups (eg. $\mathrm{C}=\mathrm{O}$ and $\mathrm{C}-\mathrm{N}$ ) of PVP [24] and metal ions which provides lots of adsorption sites for removal of $\mathrm{Cr}(\mathrm{VI})$ ions. Moreover, it is clear that chromium uptake by $\mathrm{PVP}_{-} \mathrm{Fe}_{3} \mathrm{O}_{4}$ nanocomposite is a physicochemical process, which carries electrostatic interaction.

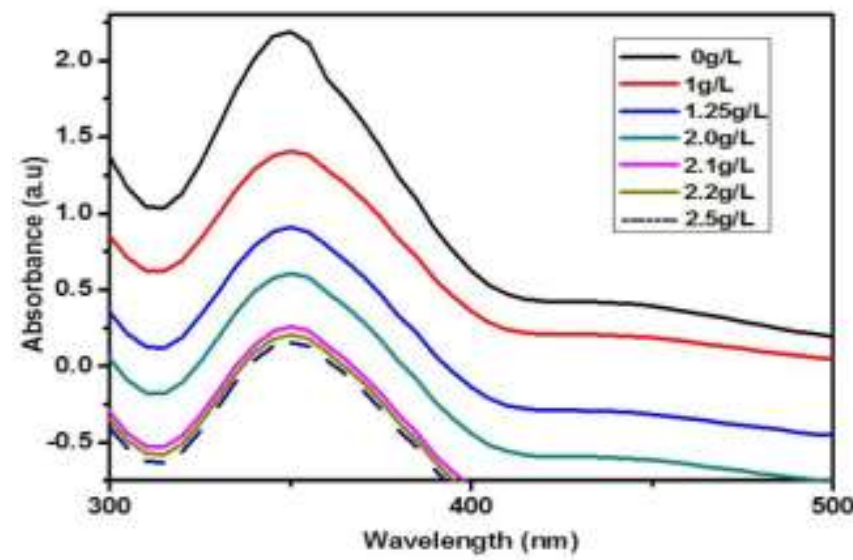

Fig.3. UV-Absorption with different concentration using PVP-Magnetite nanocomposite

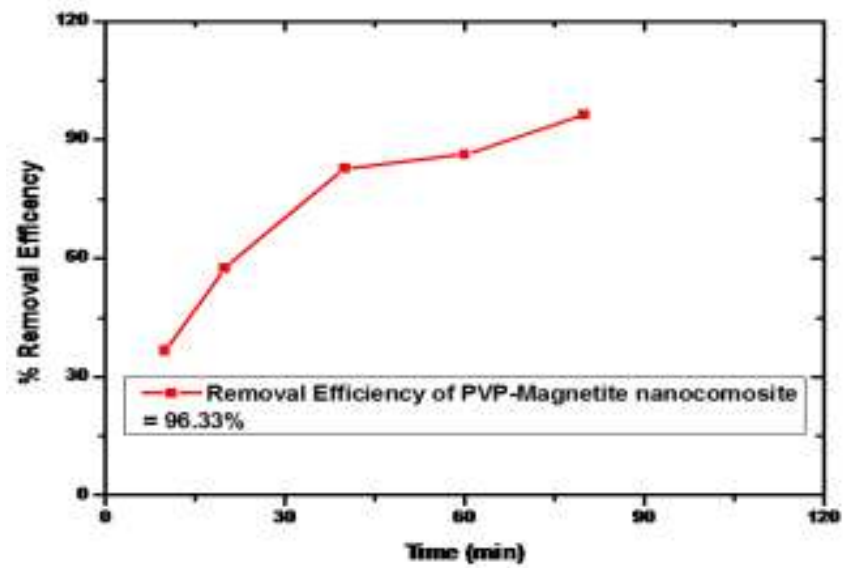

Fig.4. Removal efficiency of PVP-Magnetite nanocomposite

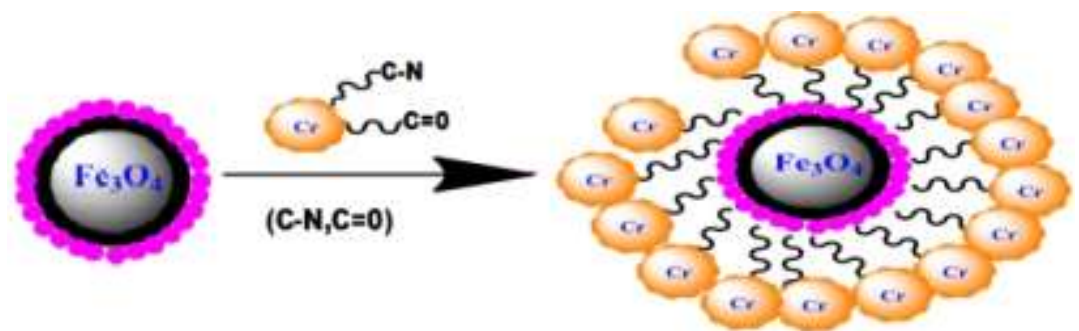

Fig.5. Schematics on representation of PVP-Magnetite nanocomposite mechanism

\section{Conclusion}

Magnetite nanoparticles were prepared by coprecipitation of $\mathrm{Fe}^{2+}$ and $\mathrm{Fe}^{3+}$ with $\mathrm{NH}_{4} \mathrm{OH}$, and then surface is grafted with polyvinyl pyrrolidone polymer. Powder X-ray diffraction shows the spinel structure for these nanoparticles. FT-IR spectra indicate that $\mathrm{C}-\mathrm{N}$ and $\mathrm{C}=\mathrm{O}$ molecules have been bound onto the surface of the magnetite nanoparticles through Fe-O. Then they could be used successfully as a magnetic cation exchanger with the possibility of removal of chromium (VI) cationic metal from water solution through grafted polymerization with polyvinyl pyrrolidone. The effect of concentration on cation separation was investigated too. From the results, it is obvious that the grafted nanocomposite shows high removal efficiency about $94 \%$. Subsequently, the removal of chromium (VI) cationic metals using PVP-magnetite nanocomposite is highly efficient. 


\section{REFERENCES}

1. Xiao Sheng Jing, Fu Qiang Liu, Xin Yang, PanPan Ling, LanJuan Li, Chao Long, AiMin Li: Adsorption performances and mechanisms of the newly synthesized N,N-di (carboxymethyl) dithiocarbamate chelating resin toward divalent heavy metal ions from aqueous media. Journal of Hazardous Materials, 167, pp.589-596(2009).

2. Yongchao Li, Zhaohui Jin, Tielong Li, Zongming Xiu, Yongchao Li, Zhaohui Jin, Tielong Li, Zongming Xiu, Science of the Total Environment: One-step synthesis and characterization of core-shell Fe@SiO ${ }^{2}$ nanocomposite for $\mathrm{Cr}(\mathrm{VI})$ reduction. 421-422.pp.260-266 (2012).

3. Robertm.powell, Robert w.puls, Sharon k. hightower, David a. Sabatini:Environ. Sci. Techno/. 29, pp.19131922(1995)

4. Md. Juned .K.Ahmed, Ahmaruzzaman,M.: A review on potential usage of industrial waste materials for binding heavy metal ions from aqueous solution. Journal of Water Process Engineering,10, pp 39-47(2016)

5. Chunming Su: Environmental implications and applications of engineered nanoscale magnetite and its hybrid nanocomposites: A review of recent literature. J.Haz.Mat. pp 0304-3894(2016).

6. Peng Yuan, Mingde Fan, Dan Yang, Hong ping He, Dong Liu, Aihua Yuan, JianXi Zhu, TianHu Chen: Montmorillonite-supported magnetite nanoparticles for the removal of hexavalent chromium [Cr(VI)] from aqueous solutions.J.Hazardous Materials,166, pp.821-829 (2009).

7. S.Vikram, M.Dhakshnamoorthy, R. Vasanthakumari, A. R. Rajamani, Murali Rangarajan, and Takuya Tsuzuki.: Tuning the Magnetic Properties of Iron Oxide Nanoparticles by a Room-Temperature Air-Atmosphere (RTAA) CoPrecipitation Method. J. of nanoscience and nanotechnology, 15, 3870-3878(2015).

8. T. Karthikeyan, S. Rajgopal, Lima Rose Miranda: Chromium(VI) adsorption from aqueous solution by Hevea Brasilinesis sawdust activated carbon. hazardous materials, 124,192-199(2005).

9. Audrey-Flore Ngomsik, Agnes Bee, Micheline Draye, Gerard Cote, Valerie Cabuil: Magnetic nano- and microparticles for metal removal and environmental applications: a review chimie, 8, 963-970(2005)

10. Inigo Larraza, Mar Lopez-Gonzalez, Teresa Corrales, Gema Marcelo: Hybrid materials: MagnetitePolyethylenimine-Montmorillonite, as magnetic adsorbents for $\mathrm{Cr}(\mathrm{VI})$ water treatment. Colloids and interface science, 385, pp 24-33(2012).

11. Klausp. Raven, Amitajain, Andrichardh. Loeppert: Arsenite and Arsenate Adsorption on Ferrihydrite: Kinetics, Equilibrium, and Adsorption Envelopes. Environ. Sci. Technol., 32, 344-349(1998).

12. Neha Gupta, Atul K. Kushwaha, Chattopadhyaya.M,C.: Adsorptive removal of $\mathrm{Pb}^{2+}, \mathrm{Co}^{2+}$ and $\mathrm{Ni}^{2+}$ by hydroxyapatite/chitosan composite from aqueous solution.Journal of the Taiwan Institute of Chemical Engineers, 43,pp.125-131(2012)

13. Guoliang Li, Zongshan Zhao, Jiyan Liu, Guibin Jiang: Effective heavy metal removal from aqueous systems by thiol functionalized magnetic mesoporous silica .Journal of Hazardous Materials, 192, pp.277-283(, 2011).

14. Rupali Rakhunde, Leena Deshpande, Juneja, H, D.: Chemical Speciation of Chromium in Water: A Review. Critical Reviews in Environmental Science and Technology, 42, 776-810 (2012).

15. Wei Wu, Quanguo He, Changzhong Jiang, Magnetic Iron Oxide Nanoparticles: Synthesis and Surface Functionalization Strategies. Nanoscale Res Lett, 3, pp.397-415(2008).

16. An-Hui Lu, Salabas, E, L, and Ferdi Schuth: Magnetic Nanoparticles: Synthesis, Protection,Functionalization, and Application. Angew. Chem. Int. Ed., 46, pp.1222 - 1244(2007)

17. Jiahua Zhu, Suying Wei, Minjiao Chen, Hongbo Gu, Sowjanya,B., Rapole; Sameer Pallavkar, Thomas C,. Ho, Jack Hopper, Zhanhu Guo: Magnetic nanocomposites for environmental remediation. Advanced Powder Technology,24 ,pp.459-467(2013).

18. Madhumita Bhaumik, Katlego Setshedi, Arjun Maity, Maurice S.Onyango: Chromium(VI) removal from water using fixed bed column of polypyrrole/Fe3O4 nanocomposite. chemical engineering journal, 110, pp.11-19(2013).

19. Wenjuan Shen, Yi Mu; Tan Xiao, Zhihui Ai: Magnetic Fe3O4-FeB nanocomposites with promoted $\mathrm{Cr}(\mathrm{VI})$ removal performance.Chemical Engineering Journal, 285, pp.57-68(2016).

20. Abu Zayed Md, Badruddoza; Zayed Bin Zakir Shawon, Md. Taifur Rahman; Kow Wei Hao, Kus Hidajat, Mohammad Shahab Uddin: lonically modified magnetic nanomaterials for arsenic and chromium removal from water. Chemical Engineering, 255,607-615(2013)

21. Alicia E. Chavez-Guajardo, Juan C. Medina-Llamas, Luis Maqueira; Cesar A.S. Andrade, Kleber G.B. Alves, Celso P. de Melo: Efficient removal of $\mathrm{Cr}(\mathrm{VI})$ and $\mathrm{Cu}$ (II) ions from aqueous media by use of polypyrrole/maghemite and polyaniline/maghemite magnetic nanocomposites. chemical engineering journal, pp.826-836(2015).

22. Vaishnavi Sureshkumar, Kiruba Daniel, S, C, G., Ruckmani, K., Sivakumar, M.: Fabrication of chitosan-magnetite nanocomposite strip for chromium removal.App.nanosci, 6, 277(2016).

23. Junyang Xian, Qing Hua, Zhiquan Jiang, Yunsheng Ma, Weixin Huang: Size-Dependent Interaction of the Poly(Nvinyl-2-pyrrolidone)Capping Ligand with Pd Nanocrystals. Langmuir, 28, 6736-6741(2012)

24. Chao Luo, Zhang Tian, Bo Yang, Li Zhang, Shiqiang Yan: Manganese dioxide/iron oxide/acid oxidized multi-walled carbon nanotube magnetic nanocomposite for enhanced hexavalent chromium removal. chemical engineering journal , 234, 256-265(2013).

25. Ballav,N., Choi,H,J.Mishra,S,B, Maity,A.: Synthesis, characterization of Fe3O4 @glycine doped polypyrrole magnetic nanocomposites and their potential performance to remove toxic $\mathrm{Cr}(\mathrm{VI})$.Ind and Eng.Chem, 20,4085(2014).

26. Fereshte Keyhanian, Shahab Shariati, Mohammad Faraji, Maryam Hesabi: Magnetite nanoparticles with surface modification for removal of methyl violet from aqueous solutions. Arb.J.Chem, 9,S348(2016).

27. Tetsuya Osaka, Takuya Nakanishi, Sangaraju Shanmugam, Shintaro Takahama, Hong Zhang: Effect of surface charge of magnetite nanoparticles on their internalization into breast cancer and umbilical vein endothelial cells. Colloids and Surfaces B: Biointerfaces, 71, 325-330(2009). 
28. Pawinee Theamdee, Rakchart Traiphol, Boonjira Rutnakornpituk, Uthai Wichai, Metha Rutnakornpituk: Surface modification of magnetite nanoparticle with azobenzene-containing water dispersible polymer.J Nanopart Res, 13,4463-4477(2011).

29. Yongji Zhang, Hui Juan Chi, Wen Hui Zhang, Youyi Sun, Qing Liang, YuGu, Riya Jing: Highly Efficient Adsorption of Copper lons by a PVP-Reduced Graphene Oxide Based On a New Adsorptions Mechanism. Nano-Micro Lett., 6, 8087(2014).

30. Yanming Wang, Daji Shang and Zhongwei Niu: Removal of Heavy Metals by Poly(Vinyl Pyrrolidone)/Laponite Nanocomposite Hydrogels. Advanced Materials Research, 63-632.pp 291-297(2013).

31. Shalini Rajput, Charles U. Pittman Jr., Dinesh Mohan: Journal of Colloid and Interface Science, 468, pp. 334-346, (2016).

32. Tiffany Marin, Paula Montoya, Oscar Arnache and Jorge A. Calderon: Influence of Surface Treatment on Magnetic Properties of FeO Nanoparticles Synthesized by Electrochemical Method.J. Phys. Chem. B (2016)

33. Md. Juned, K, Ahmed, Ahmaruzzaman, M: A review on potential usage of industrial waste materials for binding heavy metal ions from aqueous solutions. Journal of Water Process Engineering, 10 , pp. 39-47(2016).

34. Lakshmi Prasanna Lingamdinne, Janardhan Reddy Koduru, Yu-Lim Choi, Yoon-Young Chang, Jae-Kyu Yang: Studies on removal of $\mathrm{Pb}(\mathrm{II})$ and $\mathrm{Cr}(\mathrm{III})$ using graphene oxide based inverse spinel nickel ferrite nano-composite as sorbent. Hydrometallurgy(2015).

35. Susmita Sen Gupta, Krishna G. Bhattacharyya: Kinetics of adsorption of metal ions on inorganic materials: A review.Advances in Colloid and Interface Science,162, pp. 39-58(2011).

36. Jiwon Lee, Tetsuhiko Isobe, Mamoru Senna: Magnetic properties of ultrafine magnetite particles and their slurries prepared via in-situ precipitation. Colloids and Surfaces,109, pp. 121-127(1996).

37. Dhruv Mehta, Siddharth Mazumdar, S.K. Singh: Magnetic adsorbents for the treatment ofwater/wastewater-A review.Journal of Water Process Engineering,7 , pp.244-265(2015).

38. Sarita Kango, Susheel Kalia, Annamaria Cell, James Njuguna, Youssef Habibi, Rajesh Kumar: Surface modification of inorganic nanoparticles for development of organic-inorganic nanocomposites-A review. Progress in Polymer Science, 2013, 778.

39. Zhihuiai, Yingcheng, Lizhizhang and Jianrongqiu: fficient Removal of $\mathrm{Cr}(\mathrm{VI})$ from Aqueous Solution with Fe@Fe2O3 Core- Shell Nanowires.Environ. Sci. Technol.42, pp.6955-6960(2008).

40. Abir Ghosh, Madhubonti Pal, Krishna Biswas, Uday Chand Ghosh, Biswaranjan Manna: Manganese oxide incorporated ferric oxide nanocomposites (MIFN): A novel adsorbent for effective removal of $\mathrm{Cr}(\mathrm{VI})$ from contaminated water. Journal of Water Process Engineering, 7, pp.176-186(2015).

41. Jong-Hee Kim; Sang-Mun Kim, Yong-II Kim: Properties of Magnetic Nanoparticles Prepared by CoPrecipitation.Journal of Nanoscience and Nanotechnology, 14, 8739-8744(2014).

42. Jing Hu, Guohua Chen, Irene M.C. Lo: Removal and recovery of $\mathrm{Cr}(\mathrm{VI})$ from wastewater by maghemite nanoparticles. Water Research, 39, 4528-4536(2005) 